\title{
Estrutura fundiária na Bahia, Brasil: uma análise sob a ótica do índice de Gini
}

\author{
Landscape structure in Bahia, Brazil: an analysis from the Gini index
}

\author{
Sara Andrade Santos ${ }^{1}$ \\ Andréa da Silva Gomes ${ }^{2}$ \\ Mônica de Moura Pires ${ }^{3}$ (1) \\ Ronaldo Lima Gomes ${ }^{4}$
}

\begin{abstract}
Palavras-chave:
Concentração da terra

Perfil agrário

Clusters
\end{abstract}

\section{Keywords:}

Land concentration

Agrarian profile

Clusters

\begin{abstract}
Resumo
O fenômeno da alta concentração de terras, em grande parte, pode ser explicado pela história agrária de um país. A posse e uso da terra no Brasil e na Bahia revela o antagonismo suscitado pela subordinação, expropriação e exploração entre uma classe social dominante representada pelos proprietários de terra e os camponeses, o que incita a realização de uma análise contextualizada sobre a atual estrutura fundiária brasileira. Neste contexto, este trabalho faz uma análise da atual estrutura fundiária da Bahia, por meio da aplicação do índice de Gini (IG) para a terra e da técnica de agrupamento espacial (clusters), para os anos censitários de 2006 e 2017 dos 417 municípios baianos. Conforme os resultados obtidos através do cálculo do IG e da classificação utilizada, identificou-se significativa concentração fundiária na Bahia entre 2006 e 2017, muito embora tenha apresentado moderada redução nessa concentração. De acordo com a análise espacial, há formação de agrupamentos com alta concentração, especialmente em municípios da Região Geográfica Intermediária de Barreiras e a formação de clusters de municípios com baixos valores do IG nas Regiões Geográficas Intermediárias de Guanambi e Vitória da Conquista. As análises revelam que há relação entre concentração fundiária e condições socioeconômicas das regiões.
\end{abstract}

\footnotetext{
${ }^{1}$ Universidade Estadual de Santa Cruz - UESC. Departamento de Ciências Econômicas. sara.uesb@gmail.com

2 Universidade Estadual de Santa Cruz - UESC. Departamento de Ciências Econômicas. asgomes@uesc.br

${ }^{3}$ Universidade Estadual de Santa Cruz - UESC. Departamento de Ciências Econômicas. mpires@uesc.br

${ }^{4}$ Universidade Estadual de Santa Cruz - UESC. Departamento de Ciências Agrárias e Ambientais.

rlgomes.uesc@gmail.com
} 
albeit there was a moderate reduction between 2006 and 2017. According to the spatial analysis, there is a gathering with high concentration, especially in the municipalities from the Região Geográfica Intermediária de Barreiras (a Brazilian term for a geographical division used by the Instituto Brasileiro de Geografia e Estatística - IBGE), while there is a cluster of municipalities with low GI values within the Região Geográfica Intermediária de Guanambi and also in Vitória da Conquista's one. The analysis reveals the existence of a correlation between landed structure and socioeconomic aspects from the regions.

\section{INTRODUÇÃO}

No Brasil, assim como em diversos países, a colonização e a história agrária influenciaram, sobremaneira, a distribuição de terras agrícolas, delineando a sua atual configuração. Furtado (2005) descreve acerca da formação econômica do Brasil como sendo um processo histórico de difusão do progresso técnico e do uso de estímulos criados pelo sistema econômico capitalista, a fim de aumentar sua capacidade interna. Contudo, o autor ressalta que esse processo se dá sob a dificuldade de transição da economia colonial para uma economia nacional, destacando o fato de que nunca houve ruptura, no Brasil atual, com seu passado colonial, condicionando-o a uma relação de dependência de seu colonizador e, posteriormente, do setor financeiro e industrial dos países mais ricos (MIELITZ NETO; MELO; MAIA, 2010).

Historicamente, a estrutura fundiária brasileira é caracterizada pela forte concentração da terra, compreendendo-se assim que, dentre outros fatores, a origem da exploração latifundiária no Brasil, tem como base o modo de produção capitalista (PRADO JÚNIOR, 1979; FURTADO, 2005).

Considerando a grande dimensão territorial brasileira, a região Nordeste do país apresenta particularidades históricas que não favoreceram seu desenvolvimento no mesmo ritmo de outras regiões do país, como a região Sul, por exemplo (SEI, 2003). De acordo Goodman (1976), a origem de grande parte dos problemas enfrentados pelos agricultores do Nordeste advém do processo de formação social, que promoveu uma articulação entre os modos de produção pré-capitalista e capitalista. Aponta-se que as disparidades na distribuição da renda das regiões do Brasil são mais acentuadas no Nordeste, o qual apresentou rendimento mediano inferior ao restante do país, de 1992 a 2008. Além disso, apesar de ser uma região marcada pela presença de um grande número de pequenos empreendimentos rurais, o Nordeste apresenta a menor área média dos empreendimentos agrícolas (HOFFMAN; NEY, 2010).

Como na região Nordeste, o estado da Bahia apresenta também uma grande concentração de terras nas mãos dos poucos grandes proprietários, contrapondo com a maioria da população que vive em pequenas propriedades. De acordo com Santos et al. (2014), o estado da Bahia tem uma configuração semelhante à do Brasil no que se refere à estrutura fundiária, caracterizando-se como uma "herança" da colonização, quando o território foi dividido entre donatários. Dentro desta concepção da organização da terra na Bahia, a área ocupada por pequenos estabelecimentos (minifúndios) é insuficiente para garantir o sustento da maior parte das famílias que vivem nestas terras (COUTO FILHO, 2000).

Partindo-se desses elementos, o presente estudo busca analisar a estrutura fundiária da Bahia, enfatizando fatores socioeconômicos que configuram sua conformação. $\mathrm{O}$ aporte metodológico utilizado foi a aplicação do índice de Gini da terra e da técnica de agrupamento espacial (clusters) para os 417 municípios baianos e para os dois últimos censos agropecuários, de 2006 e 2017.

Espera-se que este trabalho contribua para uma análise da realidade do meio rural baiano, no que diz respeito à estrutura fundiária. A devida atenção às particularidades de cada região do estado, somada a exploração histórica de cada realidade podem fomentar melhor estruturação de políticas que visam o desenvolvimento rural.

\section{PROCEDIMENTOS METODOLÓGICOS}

\section{Área de estudo}

A área de estudo deste trabalho, refere-se ao estado da Bahia, no Brasil, formado por 417 municípios em uma unidade territorial de $564.732,450 \mathrm{~km}^{2}$, dos quais quase $53 \%$ representam área rural, com 762.620 estabelecimentos agropecuários, conforme 
Censo Agropecuário do Instituto Brasileiro de Geografia e Estatística (IBGE) de 2017. Conforme dados do IBGE (2018), o estado conta com uma população estimada em 15.344.447 habitantes, sendo 3.914.430, aproximadamente $28 \%$, residentes na zona rural.

Em 2017, o IBGE apresentou uma nova divisão regional para o Brasil, atualizando o recorte regional das Mesorregiões e Microrregiões para Regiões Geográficas Intermediárias (RGIs) e Imediatas, respectivamente, por meio do argumento da crescente diferenciação interna do espaço territorial brasileiro.

O recorte das Regiões Geográficas Imediatas e Intermediárias de 2017 incorpora as mudanças ocorridas no Brasil ao longo das últimas três décadas. [...] A região torna-se, por meio dessa opção, uma construção do conhecimento geográfico, delineada pela dinâmica dos processos de transformação ocorridos recentemente e operacionalizada a partir de elementos concretos (rede urbana, classificação hierárquica dos centros urbanos, detecção dos fluxos de gestão, entre outros), capazes de distinguir espaços regionais em escalas adequadas (IBGE, 2017, p. 35-36).

A Figura 1 mostra a localização geográfica do estado da Bahia e de suas RGIs, recorte adotado no presente estudo.

Figura 1 - Delimitação das Regiões Geográficas Intermediárias da Bahia, Brasil, 2017.

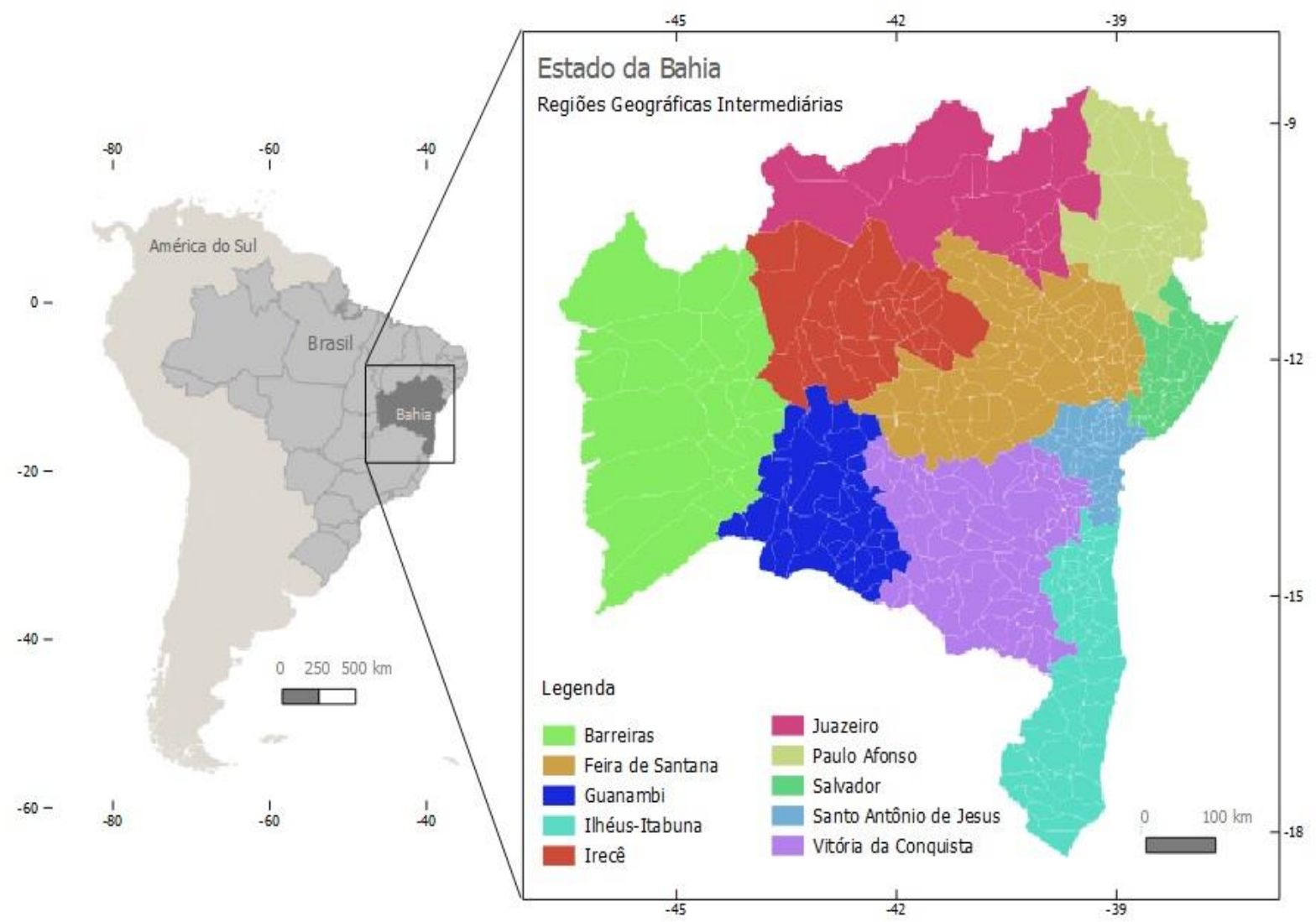

Fonte: dos Autores, 2018.

\section{Mensurabilidade e análise do Índice de Gini}

O Índice de Gini é utilizado para mensuração do grau de concentração de distribuições estatísticas, sendo comumente aplicado para a renda e a propriedade fundiária (HOFFMANN; NEY, 2010). Neste trabalho, aplica-se para medir o grau de concentração de terras, calculado por meio da relação entre a proporção acumulada de terras e a proporção dos estabelecimentos rurais, possibilitando contrastar a distribuição do uso da terra na Bahia. O índice assume valores entre zero e um, quanto mais próximo de zero, menor é a concentração de terras e quanto mais próximo de um, maior é esta concentração. 
Este indice, é medido, neste trabalho, através da seguinte form. (1) (HOFFMANN, 1998):

$G=1-\sum_{i=1}^{n}\left(Y_{i}+Y_{i-1}\right)\left(X_{i}-X_{i-1}\right)$

em que: $\mathrm{G}=$ Índice de Gini; $Y_{i}=$ a proporção acumulada das áreas rurais por estratos de área; $X_{i}=$ a proporção acumulada do número de estabelecimentos agropecuários por estratos de área.

Para o cálculo do IG foram utilizados 17 estratos de propriedade, divididos em grupos de área que variam entre mais de 0 a menos de 0,1 hectares até de 2.500 hectares a mais, foi excluída, em todas as estimativas, a categoria "produtor sem área" criada no Censo Agropecuário de 2006, como informa Hoffmann e Ney (2010). Os 17 estratos de área se dividem nos seguintes grupos: mais de 0 a menos de 0,1 ha; de 0,1 a menos de 0,2 ha; de 0,2 a menos de 0,5 ha; de 0,5 a menos de 1 ha; de 1 a menos de 2 ha; de 2 a menos de 3 ha; de 3 a menos de 4 ha; de 4 a menos de 5 ha; de 5 a menos de 10 ha; de 10 a menos de 20 ha; de 20 a menos de 50 ha; de 50 a menos de 100 ha; de 100 a menos de 200 ha; de 200 a menos de 500 ha; de 500 a menos de 1000 ha; de 1000 a menos de 2500 ha e de 2500 ha e mais.

Utilizou-se a classificação feita por Câmara (1949) que mede a concentração da posse da terra de acordo com o IG (Tabela 1), em que qualquer valor acima de 0,500 pode ser considerado inadequado do ponto de vista distributivo (CÂMARA, 1949).

Tabela 1 - Classificação do índice de Gini para concentração da posse da terra.

\begin{tabular}{ll}
\hline Índice de Gini & Classificação \\
\hline 0,000 a 0,100 & Concentração Nula \\
0,101 a 0,250 & Concentração Nula a Fraca \\
0,251 a 0,500 & Concentração Fraca a Média \\
0,501 a 0,700 & Concentração Média a Forte \\
0,701 a 0,900 & Concentração Forte a Muito Forte \\
0,901 a 1,000 & Concentração Muito Forte a Absoluta \\
\hline
\end{tabular}

Fonte: Câmara (1949, p. 517).

Os resultados obtidos através do cálculo do IG podem ser associados, em nível espacial, entre determinadas áreas, sendo possível a identificação de comportamentos semelhantes, configurando um sistema de agrupamentos, denominados de clusters.

Segundo Perobelli et al. (2007), a Análise Exploratória de Dados Espaciais (AEDE) está fundamentada nos aspectos espaciais da base de dados, tratando, diretamente de questões como dependência e heterogeneidade espacial. Em outras palavras, este método pretende descrever a distribuição espacial, os padrões de associação espacial, a verificação da existência de diferentes regimes espaciais ou outras formas de instabilidade espacial, além de identificar observações atípicas.

Esta técnica estatística contribui para a análise do perfil da estrutura fundiária baiana através da identificação de similaridades na configuração da concentração da posse da terra no estado. Por meio do índice de Moran (I Moran), é possível medir a dependência espacial entre áreas a partir do cálculo da autocorrelação espacial como uma covariância do produto dos desvios em relação à média, relacionando o valor atribuído a determinado fenômeno, em um dado local, ao valor médio dos seus vizinhos (PEROBELLI et al., 2007). Dessa forma, a aplicação, através do I de Moran, leva em conta, neste caso, a formação de clusters entre municípios que apresentem características comuns quanto ao nível de desigualdade da posse da terra na Bahia.

\section{RESULTADOS E DISCUSSÃO}

\section{Concentração fundiária na Bahia: evidências de agrupamento espacial}

A partir da classificação da concentração da terra, indicada por Câmara (1949), retrata-se a espacialização da distribuição de terras por municípios, no estado da Bahia (Figura 2). Quanto mais escura a cor verde, maior o valor do IG e, consequentemente, maior a concentração de terras. 
Figura 2 - Índice de Gini para terra dos municípios da Bahia para 2006 e 2017, por regiões geográficas intermediárias.

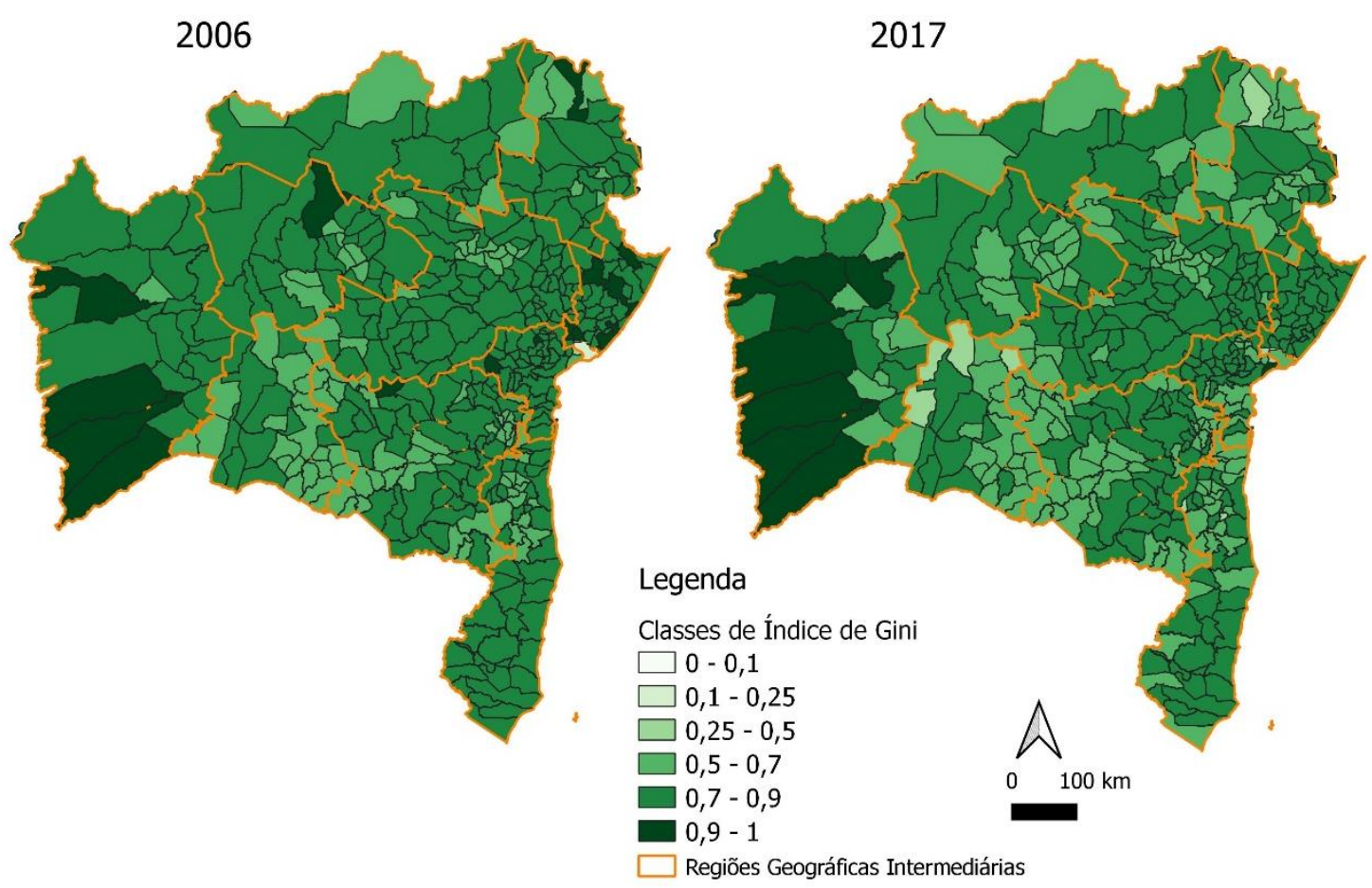

Fonte: dos Autores, 2018.

Nota: O município de Madre de Deus obteve valor zero para o IG, pois não havia dados para este município nos Censos Agropecuários de 2006 e 2017 do IBGE.

Em termos da localização espacial, atenta-se que a maior parte dos municípios baianos possui IG maior que 0,500 (414 municípios em 2006 e 406 em 2017). A classificação identificada como forte a muito forte $(0,700$ a 0,900$)$ concentra $o$ maior número de municípios em ambos os anos estudados (71\% em 2006 e 55\% em 2017), mesmo apresentando uma queda de $16 \%$ entre um período e outro. Entretanto percebe-se um aumento do número de municípios na classe de 0,500 a 0,700, passando de $24 \%$ dos municípios em 2006 para mais de 40\% em 2017. Observa-se ainda a presença de alguns municípios com concentração muito forte a absoluta (IG de 0,900 a 1), de 15 municípios em 2006, para 8 em 2017.

Observando a Figura 3, pode-se constatar leve queda na concentração de terras na Bahia, de 0,752 em 2006 para 0,713 em 2017. Em 2006, 46,5\% dos municípios estavam abaixo da média e 53,5\% acima em 2017.

Esses números apontam, que a concentração de terras no estado da Bahia, entre os dois períodos analisados, reduziu $22,5 \%$ na classificação de forte a muito forte, e quase $47 \%$ na concentração muito forte a absoluta. Apesar disso, observa-se poucos municípios inseridos nas três primeiras classificações de melhor condição na distribuição das terras por estabelecimentos agropecuários.

As RGIs de Salvador e de Barreiras aglomeraram a maioria dos municípios com IG de 0,900 a 1 , para o ano de 2006, fortalecendo esta concentração na RGI de Barreiras, no ano de 2017. Enquanto isso, no mesmo ano, na RGI de Guanambi quase metade dos municípios apresentaram IG de 0,251 a 0,500, considerado como uma concentração de fraca a média. $\mathrm{Na}$ Tabela 2 está o ranking dos 10 municípios com menor e maior valor do IG e a Região Geográfica Intermediária pertencente, para os anos de 2006 e 2017. 
Figura 3 - Quantidade e percentagem de municípios baianos por tipo de classificação fundiária, de acordo com o índice de Gini para a terra de 2006 e 2017.

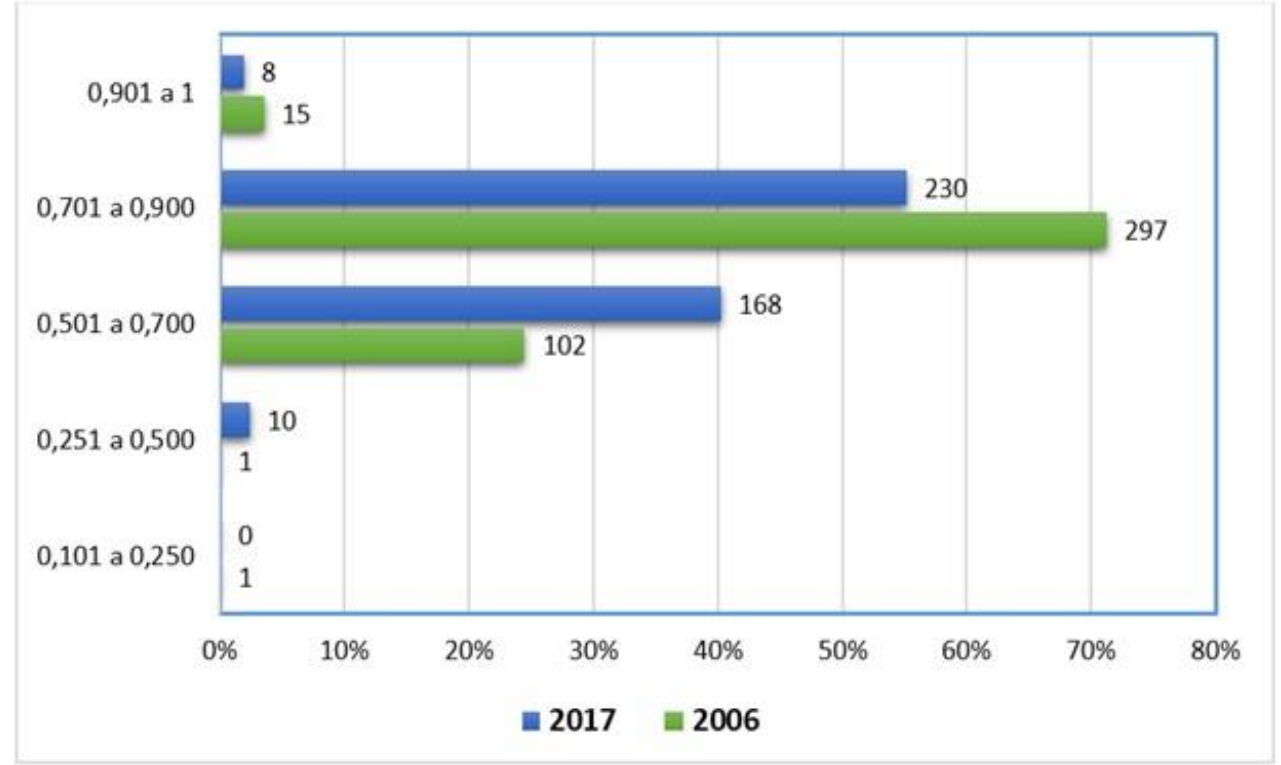

Fonte: dos Autores, 2018.

Tabela 2 - Ranking dos 10 maiores e dos 10 menores valores do IG por Regiões Geográficas Intermediárias (RGI) da Bahia em que estão localizados, 2006 e 2017.

\begin{tabular}{|c|c|c|c|c|c|}
\hline \multicolumn{6}{|c|}{2006} \\
\hline Municípios & $\begin{array}{c}10 \text { menores } \\
\text { IG }\end{array}$ & $\begin{array}{ll}\text { ores do IG } & \\
& \text { RGI }\end{array}$ & Municípios & 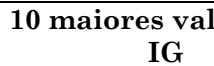 & $\begin{array}{ll}\operatorname{ces} d o & \text { RGI } \\
\end{array}$ \\
\hline Salvador & 0,213 & Salvador & $\begin{array}{l}\text { São Francisco } \\
\text { do Conde }\end{array}$ & 0,982 & Salvador \\
\hline Itaparica & 0,489 & $\begin{array}{c}\text { Santo Antônio de } \\
\text { Jesus }\end{array}$ & Sapeaçu & 0,970 & $\begin{array}{c}\text { Santo Antônio de } \\
\text { Jesus }\end{array}$ \\
\hline $\begin{array}{ll}\text { Serra do } & \text { do } \\
\text { Ramalho } & \end{array}$ & 0,511 & Guanambi & $\begin{array}{l}\text { Itaguaçu da } \\
\text { Bahia }\end{array}$ & 0,935 & Irecê \\
\hline Ponto Novo & 0,514 & Juazeiro & Correntina & 0,932 & Barreiras \\
\hline Ibicaraí & 0,533 & Ilhéus-Itabuna & Entre Rios & 0,929 & Salvador \\
\hline Chorrochó & 0,537 & Paulo Afonso & Jaborandi & 0,919 & Barreiras \\
\hline Barro Preto & 0,545 & Ilhéus-Itabuna & Rio Real & 0,918 & Salvador \\
\hline Ibipitanga & 0,547 & Guanambi & Cocos & 0,917 & Barreiras \\
\hline Vera Cruz & 0,556 & $\begin{array}{c}\text { Santo Antônio de } \\
\text { Jesus }\end{array}$ & Ibicoara & 0,917 & $\begin{array}{l}\text { Vitória da } \\
\text { Conquista }\end{array}$ \\
\hline Tanque Novo & 0,557 & Guanambi & Inhambupe & 0,916 & Salvador \\
\hline & & & 2017 & & \\
\hline Itaparica & 0,308 & $\begin{array}{c}\text { Santo Antônio de } \\
\text { Jesus }\end{array}$ & Correntina & 0,945 & Barreiras \\
\hline $\begin{array}{ll}\text { Serra do } & \text { do } \\
\text { Ramalho } & \end{array}$ & 0,343 & Guanambi & Barreiras & 0,931 & Barreiras \\
\hline Saubara & 0,369 & Salvador & Cocos & 0,923 & Barreiras \\
\hline Sítio do Mato & 0,389 & Guanambi & Vera Cruz & 0,922 & $\begin{array}{c}\text { Santo Antônio de } \\
\text { Jesus }\end{array}$ \\
\hline $\begin{array}{l}\text { Firmino } \\
\text { Alves }\end{array}$ & 0,455 & Ilhéus-Itabuna & São Desidério & 0,917 & Barreiras \\
\hline Macururé & 0,457 & Guanambi & Jaborandi & 0,915 & Barreiras \\
\hline $\begin{array}{ll}\text { Lauro de } \\
\text { Freitas }\end{array}$ & 0,464 & Salvador & $\begin{array}{l}\text { Riachão das } \\
\text { Neves }\end{array}$ & 0,913 & Barreiras \\
\hline Paratinga & 0,473 & Paulo Afonso & Cotegipe & 0,906 & Barreiras \\
\hline Ibipitanga & 0,495 & Guanambi & $\begin{array}{l}\text { São Francisco } \\
\text { do Conde }\end{array}$ & 0,884 & Salvador \\
\hline $\begin{array}{l}\text { São José da } \\
\text { Vitória }\end{array}$ & 0,495 & Ilhéus-Itabuna & Brejões & 0,877 & $\begin{array}{c}\text { Santo Antônio de } \\
\text { Jesus }\end{array}$ \\
\hline
\end{tabular}

Fonte: dos Autores, 2018. 
Constata-se que a RGI de Salvador inclui os municípios com menor e maior valores do IG para 2006, são eles Salvador $(0,213)$ e São Francisco do Conde $(0,982)$, respectivamente. Para o ano de 2017, o município de Itaparica, localizado na RGI de Santo Antônio de Jesus, obteve o menor valor do IG $(0,308)$, enquanto Correntina, localizado na RGI de Barreiras, apresentou o maior valor do IG $(0,945)$.

A RGI de Salvador é a principal região econômica do estado e a que possui maior densidade demográfica, tendo Salvador, capital da Bahia, como o município que absorve, proporcionalmente, a maior parte da riqueza gerada no território baiano sendo também um polarizador para os municípios ao seu entorno que formam a região metropolitana, especialmente, no setor industrial pela sua especialização na produção de insumos industriais, principalmente químicos $\mathrm{e}$ petroquímicos (CARVALHO; CARVALHO; GÓES, 2011).

As características singulares da RGI de Salvador nos ajuda a compreender os baixos valores de IG para a terra, já que concentra as principais atividades industriais e de serviços do estado da Bahia. Dessa maneira, essa região aglutina um maior contingente populacional, o que acaba por atrair melhores e maiores investimentos.

Efetivamente, a vinculação histórica da economia baiana às atividades comerciais de exportação, em torno de determinados produtos (cana, fumo, cacau, etc.) fez com que as regiões mais dinâmicas se localizassem próximas do litoral (faixa de $200 \mathrm{~km}$. de largura), tendo como principal centro de comercialização a cidade de Salvador, numa "economia voltada para fora" (IVO, 1983, p. 37, grifo do autor).

Em relação ao município de São Francisco do Conde, também situado na RGI de Salvador, o maior valor do IG para a terra no ano de 2006, o qual permanece alto em 2017, evidencia uma economia baseada em atividades agrícolas (principalmente cana de açúcar), pecuária, silvicultura, mas também a indústria de transformação (IBGE, 2018). Além disso, a partir dos anos de 1950, o município passou por uma nova organização territorial com a exploração petrolífera, via implantação da Refinaria Landulpho Alves (RLAM), que interferiu na economia, geração de empregos e dinâmica social (MARTINS JÚNIOR; BARBOSA, 2017).
Carvalho (2008) aponta ainda, que os municípios de São Francisco do Conde e Vera Cruz (situado na RGI de Santo Antônio de Jesus), possuem os níveis mais extremados de concentração da riqueza, e, consequentemente, um maior número de pobres em relação aos demais municípios da RGI de Salvador, o que ajuda na compreensão dos altos valores de IG observados nesses municípios. Ademais, o IBGE (2018) aponta que em uma área total de 10.991ha, quatro estabelecimentos agropecuários possuem áreas superiores a 1.000ha em São Francisco do Conde, enquanto que $62,5 \%$ da área total de Vera Cruz pertence a somente três estabelecimentos.

Na RGI de Barreiras nota-se um aumento do número de municípios com índices de concentração de terra muito forte (IG entre 0,901 a 1,000) no período de 2006 a 2017. Em 2006, do total de 24 municípios dessa RGI, quatro municípios apresentaram concentração considerada muito forte, já em 2017, sete municípios apresentaram índices nessa faixa. Esta condição pode estar associada à expansão da fronteira agrícola e, a importância do agronegócio nessa localidade, que exibe uma estrutura moderna de grandes propriedades, cuja produção destina-se ao mercado externo (BARBOSA, 2016).

O processo de abertura da fronteira agrícola na Bahia, no período de 1970 a 1980, foi um dos importantes fatores na determinação das mudanças no espaço rural baiano, condicionando em certa medida, as formas de acesso e uso do solo. Ivo (1983) afirma que a maior incorporação de áreas de estabelecimentos rurais para "Além São Francisco", no estado, ocorreu no sentido Oeste, sobretudo no município de Barreiras, considerado o mais importante centro regional do Oeste baiano (IVO, 1983).

$\mathrm{O}$ autor supracitado salienta ainda que a irradiação desse processo pode ser atribuída, principalmente, ao seu bioma cerrado, de relevo plano, terras fartas a baixos preços e grande disponibilidade hídrica. Santos (2016, p. 10) aponta que esses fatores

[...] concorreram para a implementação de uma agricultura moderna, capaz de atender às demandas a nível nacional $\mathrm{e}$ internacional, tendo como os principais sujeitos os sulistas, que de certa forma, já dispunham de conhecimentos técnicos adquiridos em suas regiões de origem.

A RGI de Barreiras faz parte da região do MATOPIBA (acrónimo que designa uma 
extensão geográfica formada pelos estados do Maranhão, Tocantins, Piauí e Bahia), situada ao norte do Cerrado brasileiro. A região do MATOPIBA trabalha, predominantemente, com o cultivo de grãos, sendo a soja o principal produto de exportação, tendo a região oeste da Bahia como maior produtor desse grão (SEI, 2017). A Rede Social de Justiça e Direitos Humanos (RSJDH) e a ActionAid (2017) retratam que a alta concentração de terras nessa região deve-se, entre outros fatores, ao preço da terra que se mostra crescente.

Somado a esta condição Freitas, Rossini e Queirós (2014), apontam que a aquisição de terras, para fins agrícolas, por estrangeiros, na região do MATOPIBA, também constitui um fator explicativo para a alta concentração de terras. De acordo os autores, empresas da Holanda, dos EUA e do Reino Unido atuam no mercado de terras e na produção de grãos na região baiana pertencente ao MATOPIBA. Dessa maneira, esse cenário apresenta uma situação de risco aos pequenos produtores que, dentre outras razões, não conseguem competir com o agronegócio e, muitas vezes, acabam sendo privados do acesso à terra pelo seu alto valor de especulação, resultando em uma estrutura fundiária concentrada.

Ainda de acordo com os dados verifica-se que a maior parte dos municípios baianos está inserida na classificação forte a muito forte em ambos os anos estudados (Figura 2). Entretanto, houve uma moderada diminuição no número de municípios que apresentam esta classificação,

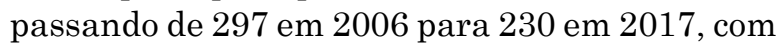
um aumento de quase $40 \%$ de municípios inseridos na classificação anterior (concentração de média a forte). Dessa forma, nota-se, espacialmente, uma diminuição da concentração no estado, ressaltando os municípios da RGI de Guanambi que compõem o ranking dos 10 menores valores do IG em 2017 (Tabela 2).

A maioria desses municípios encontra-se no semiárido baiano, (região central do estado que abrange, além da RGI de Guanambi, as RGIs de Vitória da Conquista, Feira de Santana, Irecê Juazeiro e Paulo Afonso).

De acordo com o Instituto Nacional do Semiárido - INSA (2017), o semiárido possui uma extensão territorial de $445.613 \mathrm{~km}^{2}$, quase $79 \%$ dele encontra-se no estado da Bahia. Dos 417 municípios baianos, 278 estavam inseridos nesse espaço, abarcando metade da população do estado, e que, conforme Barbosa (2016), comporta o maior número de estabelecimentos familiares da Bahia. Em 2017, por exemplo, existiam $\quad 591.213 \quad$ estabelecimentos (aproximadamente $78 \%$ do total de estabelecimentos agropecuários da Bahia) (IBGE, 2018).

No semiárido há irregularidade de chuvas, o que a torna uma região de aridez, como aponta Baptista e Campos (2013). Este fator somado ao fraco dinamismo, expõe um ambiente de frágil sistema de armazenamento de água, o qual não foi capaz de superar tal situação para transformar a condição socioeconômica da população que vive na área rural.

Ademais, o poder público tem concentrado sua atuação do combate à seca na região semiárida por meio da construção de grandes obras de impacto, a exemplo da transposição das águas do rio São Francisco, da construção de açudes e da implementação de grandes programas de agricultura irrigada. Entretanto, são os grandes e médios agricultores que tem sido o público atendido prioritariamente por esses programas, favorecendo a implantação de agricultura irrigada modernizada e excluindo a maioria da população desse processo (BARBOSA, 2012).

Nesta direção, entende-se que, mesmo que esta região apresente uma pequena diminuição da concentração de terras em alguns municípios, entretanto, sua estrutura fundiária ainda é concentrada. Sob essa condição, a região semiárida carece de políticas de promoção ao desenvolvimento rural adequadas as suas particularidades e que visem considerar a satisfação de um conjunto de requisitos de bemestar e qualidade de vida, somados à integração dos mercados regionais e nacionais por meio do aumento da produtividade dos pequenos agricultores (FURTADO, 1959).

De acordo com Oliveira (2013), nessa região, predominam a pecuária extensiva e as atividades agropastoris de subsistência desde meados do século XIX, considerada atividade mais fácil para adentrar nas caatingas do sertão. Apesar da importância na ocupação do território, essa atividade era secundária, servindo de "suporte" a atividade açucareira, viabilizando o abastecimento, sobretudo de carne, aos engenhos. Contudo a sua relevância ainda está presente em todo o semiárido brasileiro, visto que quase $40 \%$ de toda a área dos estabelecimentos agropecuários, em hectares, possuem pastagens, e na Bahia esse percentual chega a quase $45 \%$ (INSA, 2017).

Historicamente, o semiárido não tinha "status" de região de atratividade para o capital, especialmente pelas condições climáticas, caracterizadas por baixos índices pluviométricos, e de difícil acesso e escoamento da produção, diferentemente das regiões litorâneas de clima mais ameno e facilidades 
para escoamento da produção, e também de maior contingente populacional (OLIVEIRA, 2013).

Nesse processo de desenvolvimento da Bahia, "restou" à agricultura familiar pouco capitalizada, os solos mais áridos para as atividades agropastoris, como o sertão baiano. Assim, de acordo com Sampaio (2008) essas atividades ocupavam pequenas áreas, preferencialmente nas beiras dos rios, ou como apontado por Oliveira (2013), em extenso latifúndio pertencente à aristocracia rural, e uma posição secundária no processo de industrialização da Bahia, ficando à margem dos recentes polos dinâmicos da economia baiana.

Quanto à RGI de Ilhéus -Itabuna, a maioria de seus municípios possui concentração de forte a muito forte tanto em 2006 como em 2017, com pequena diminuição da concentração no ano de 2017. Segundo Pedreira (2004), parcela significativa do crescimento das atividades agropecuárias dessa região, especialmente no Extremo Sul nos anos 1980, se deu pela ocupação de áreas de matas e florestas naturais, "viabilizado" pelo desmatamento da vegetação natural local.

As facilidades de transporte rodoviário, a existência de terras de baixo valor, os incentivos dos governos estadual e federal e as altas potencialidades naturais da região foram atraindo para lá diversos agentes econômicos, tais como madeireiros, pecuaristas, agricultores, empresas reflorestadoras e, por fim, as indústrias do setor de celulose e papel (PEDREIRA, 2004, p. 1008-1009).

Esses fatores que compõem a ocupação desse território podem estar associados à tendência de intensificação do grau de concentração de terras no Extremo Sul, demonstrada por Oliveira, Oliveira e Araújo (2007). Ademais, o alto índice desta concentração, observado na Figura 2, pode ser explicado, em parte, pelas atividades agrícolas desenvolvidas na região. Sobre isso, Santos et al. (2014), salientam que a presença de monocultivos tradicionais, seja na lavoura permanente ou temporária, geralmente, exigem extensas faixas de terra, a exemplo do cacau, do café e da cana de açúcar, sendo que esta última chega a ocupar $77 \%$ de toda a área plantada.

Conforme Carvalho e Bajay (2006), destacase ainda a expansão da silvicultura, motivada pela chegada de empreendimentos do setor de papel e celulose atraídos pelas condições edafoclimáticas favoráveis da região como precipitação pluviométrica, condições de solo e insolação. Entretanto, este movimento da configuração agropecuária da Bahia, através da intensificação da atividade silvícola, denota um paradoxo entre o crescimento do emprego na zona urbana e seus efeitos negativos as pequenas unidades produtoras familiares. Alguns desses efeitos se materializam na concentração de terras, substituição de lavouras tradicionalmente desenvolvidas na região, diminuição da população rural, aumento dos conflitos sociais no campo, devastação da Mata Atlântica e implantação de grandes maciços florestais (OLIVEIRA; OLIVEIRA; ARAÚJO, 2007).

Quanto à área ao norte da RGI de Ilhéus Itabuna, que abrange, principalmente o território de identidade Litoral Sul, alguns aspectos de sua formação histórica auxilia a compreender a atual concentração de terras ali existente. Historicamente, vários fatores geraram uma estrutura agrária concentradora nessa região, como, por exemplo, a migração do capital proveniente do Nordeste do país para a região cacaueira da Bahia, sul do estado. Esse descolamento do capital propiciou o aumento das áreas com cacau na Bahia, beneficiando produtores mais capitalizados (ROCHA, 2008).

No final dos anos de 1980, a atividade cacaueira entra em colapso por conta de diversos fatores, dentre os mais relevantes a disseminação da doença conhecida como vassoura de bruxa (Moniliophtera perniciosa) e queda de preço do cacau no mercado internacional. Apesar da relevância econômica e social, essa crise, pouco efeito teve sobre a desconcentração de terras. No entanto, muitos produtores para se capitalizar, começaram a vender terras, enquanto outros tantos resistiam a isso, em função do "capital imobilizado" representado pelo cacaual. Assim, para se capitalizarem, inúmeros produtores procuraram diversificar a produção, implantando sistemas consorciados de cultivos como cacaueiroseringueira dentre outros arranjos produtivos.

Ademais, a fim de reduzir os custos com mão de obra passou-se a adotar a parceria (conforme o Estatuto da Terra (s1964), art. 96, VI, contrato agrário pelo qual uma pessoa se obriga a ceder a outra, por tempo determinado ou não, o uso específico de imóvel rural, de parte ou partes do mesmo, incluindo, ou não, benfeitorias, outros bens e ou facilidades, com o objetivo de nele ser exercida atividades ligadas a exploração agrícola) nas áreas com cacau. O emprego do sistema de parceria no cacau foi uma forma de "socializar" os prejuízos decorrentes da crise que se instalou na região sul da Bahia, o que permitiu ao proprietário da terra minimizar 
suas perdas, porém às "custas" de grande pobreza no meio rural. Entretanto, sob condições de preços mais remuneradores, os produtores não "socializam" os ganhos, e novamente o trabalhador e sua família não participam desse excedente de capital (SANTOS et al., 2014).
Espacializando o IG a partir do Índice de Moran local, é possível identificar formação de clusters da estrutura fundiária na Bahia, formados por municípios internamente homogêneos com altos ou baixos valores do IG (Figura 4).

Figura 4 - Aglomerações espaciais para concentração de terra dos municípios do estado da Bahia em 2006 e 2017, de acordo com a técnica de Moran Local

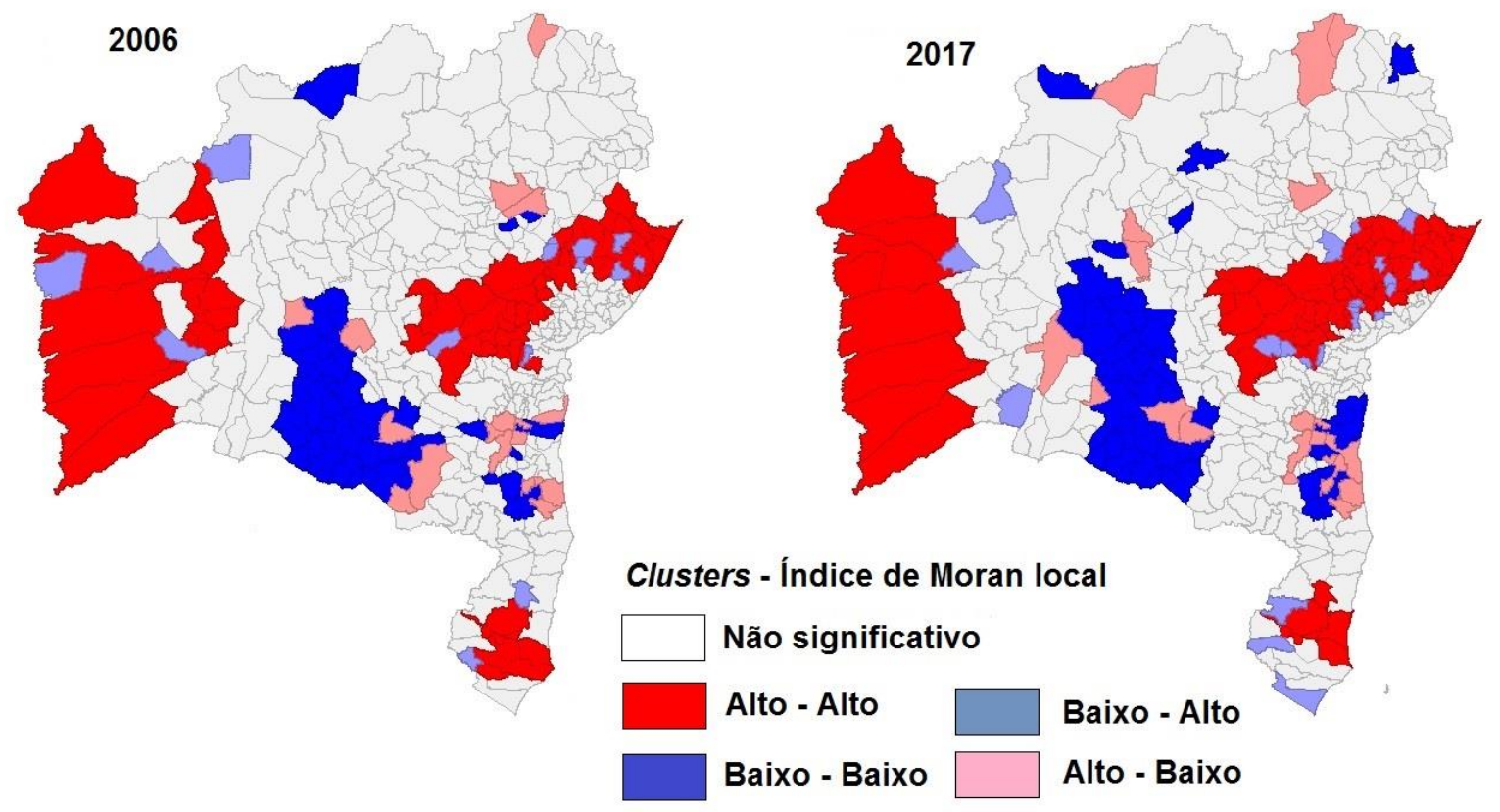

Fonte: dos Autores, 2018.

Nota: A técnica de Moran apresenta a formação de clusters, através de associações espaciais do tipo alto-alto (AA) - manchas em vermelho -, para municípios em pior situação relativa a esse fator, ou baixo-baixo (BB) - manchas em azul-escuro -, para municípios em melhor situação cercados de semelhantes. As outras duas situações possíveis são destacadas em azul-claro, para municípios em melhor situação relativa cercados por outros em situação mais precária, alto-baixo (AB), e em vermelho claro, para municípios em pior situação cercados por aqueles em situação relativamente mais favorável, baixo-alto (BA) (SEI, 2014).

Verifica-se na formação dos clusters mais expressivos, a RGI de Barreiras, tanto em 2006 como em 2017, ratificando a força do agronegócio nesta região (Figura 4). Além de demonstrar um aglomerado de forte concentração que abrange as RGIs de Salvador, Feira de Santana e Santo Antônio de Jesus. Quanto à RGI Ilhéus Itabuna, no ano de 2006 e 2017, essa apresentou cluster baixo-baixo e outra alto-baixo (municípios em pior situação cercados por aqueles em melhor situação relativa) mais ao norte, exibindo uma nova e maior região de cluster alto-alto ao sul da região em 2017.

Percebe-se ainda uma configuração semelhante entre os anos de 2006 e 2017 na formação dos agrupamentos espaciais para concentração de terra dos municípios do estado da Bahia. Conquanto, a região que abrange, em sua maior parte, as RGIs de Guanambi e Vitória da Conquista, situadas, em sua maioria na região Semiárida da Bahia, aglomera valores mais baixos do IG em 2006 e 2017, confirmando o exposto na Figura 2.

\section{CONSIDERAÇÕES FINAIS}

O estado da Bahia possui características históricas marcantes quanto à evolução de sua estrutura fundiária, denotando uma expressiva desigualdade quanto à posse e ao uso de terras para fins agropecuários. Este fato pôde ser confirmado pelo IG terra nos anos de 2006 e 2017 que identificou um alto grau de concentração da terra na maioria dos municípios 
baianos, apesar de pequena diminuição da concentração de forte a muito forte do ano de 2006 para 2017.

O perfil fundiário concentrador da Bahia se manifesta de forma bastante heterogênea espacialmente, apresentando a formação de clusters regionais de alta concentração de terra (no oeste, extremo sul e em partes da Região Metropolitana de Salvador e do Recôncavo) e clusters de menor concentração de terra, especialmente no semiárido do estado.

Pode-se notar que o tipo de cultivo, o local de produção e o tipo de mão de obra empregada parecem afetar o grau da concentração fundiária, explicitando assim a relevância de fatores socioeconômicos, ambientais e, sobretudo, históricos para explicar o processo de alta concentração de terras na Bahia. Esse fator histórico permite-nos refletir sobre a necessidade de se delinear políticas que possibilitem "quebrar" esse círculo vicioso da distribuição de terras no estado. Ademais, a heterogeneidade observada na estrutura fundiária da Bahia revela a necessidade de medidas de política que considerem as especificidades locais, a dinâmica e a infraestrutura existente, a fim de atingir melhor distribuição de terras.

\section{REFERÊNCIAS}

BAPTISTA, N. Q.; CAMPOS, C. H. Caracterização do Semiárido Brasileiro. In: CONTI, I. L.; SCHROEDER, E. O. (Coord.). Convivência com o Semiárido Brasileiro: autonomia e protagonismo social. Brasília: IABS, 2013. p. 45-50.

BARBOSA, C. R. Pobreza rural sob a ótica multidimensional e estrutura fundiária: uma análise do Estado da Bahia. Dissertação (Mestrado em Economia Regional e Políticas Públicas) - Ilhéus: UESC. 2016.

BARBOSA, M. S. A percepção de agricultores familiares e formuladores de políticas: o reuso da água no semiárido baiano. Tese (Doutorado em Administração) Salvador: UFBA. 2012.

CÂMARA, L. A. Concentração da Propriedade Agrária no Brasil. Rio de Janeiro: Boletim Geográfico. v.7, n.77, p.516-528, 1949. Disponível em: <https://biblioteca.ibge.gov.br/visualizacao/per iodicos/19/bg_1949_v7_n77_ago.pdf >. Acesso em: 04 mar. 2020.

CARVALHO, C. B. de; BAJAY, S. V. O setor agropecuário no estado da Bahia: perspectivas econômicas e intensidade energética. Encontro de Energia no Meio Rural, 6, 2006, Campinas. Disponível em: <http://www.proceedings.scielo.br/scielo.php? pid=MSC0000000022006000200018\&script $=$ s ci_arttext>. Acesso em: 20 set. 2018.

CARVALHO, C. V. de; CARVALHO, I. M. M. de; GÓES, T. R. Dinâmica econômica e socioespacial da metrópole baiana em uma economia globalizada. Textos para Discussão, 2011, n. 1, p. 1-20.

CARVALHO, I. M. M. de. Trabalho, renda e pobreza na Região Metropolitana de Salvador. In: CARVALHO, I. M. M.; PEREIRA, G. C. (Coord.) Como anda Salvador e sua região metropolitana. Salvador: EDUFBA, 2008. https://doi.org/10.7476/9788523209094

COUTO FILHO, V. de A. Os "novos rurais" baianos. In: CAMPANHOLA, C.; SILVA, J. G. da. (Coord.). O novo rural brasileiro: uma análise estadual - Nordeste. São Paulo: Embrapa, 2000. p. 97 - 137.

FREITAS, E. P. de; ROSSINI, R. E.; QUEIRÓS, $M$. O poder das empresas transnacionais sobre o território brasileiro: reflexões a partir do sector sucroenergético. XIII Colóquio Internacional de Geocrítica: El control del espacio y los espacios de control Barcelona, 2014. Disponível em:

<http://www.ub.edu/geocrit/coloquio2014/Elis a\%20Pinheiro\%20de\%20Freitas.pdf>. Acesso em: 05 mar. 2020.

FURTADO, C. Formação econômica do Brasil. 32. ed. São Paulo: Nacional, 2005 [1959].

FURTADO, C. Operação Nordeste. Rio de Janeiro: MEC, 1959.

GODMAN, D. Estrutura rural, excedente agrícola e modos de produção no Nordeste brasileiro. Pesquisa e Planejamento Econômico, v. 6, n. 2, p. 489-534, 1976. Disponível em: <http://repositorio.ipea.gov.br/handle/11058/6 797>. Acesso em 11 nov. 2018.

HOFFMANN, R. O índice de desigualdade de Theil-Atkinson. Revista de Econometria, v. 11, n. 2, p.143-160, 1998. https://doi.org/10.12660/bre.v11n21991.3001

; NEY, M. G. Estrutura fundiária e propriedade agrícola no Brasil: grandes regiões e unidades da federação (de 1970 a 2008). Brasília: Ministério do Desenvolvimento Agrário, 2010.

INSA - INSTITUTO NACIONAL DO SEMIÁRIDO. Sinopse do censo demográfico para o Semiárido brasileiro. Campinha Grande: INSA, 2017. Disponível em: <https://portal.insa.gov.br/acervo- 
livros/198-sinopse-do-censo-demografico-parao-semiarido-brasileiro>. Acesso em 10/10/2018.

IBGE - INSTITUTO BRASILEIRO DE GEOGRAFIA E ESTATÍSTICA - IBGE. Censo Agropecuário 2006: Brasil, Grandes Regiões e Unidades da Federação. Rio de Janeiro, IBGE, 2006.

Censo Agropecuário 2006: Brasil, Grandes Regiões e Unidades da Federação. Segunda apuração. Rio de Janeiro, IBGE, 2012.

Censo Agropecuário 2017. Rio de Janeiro, IBGE, 2018. Disponível em: $<$ https://sidra.ibge.gov.br/tabela/6710>. Acesso em: 01 ago. 2018.

Divisão regional do Brasil em regiões geográficas imediatas e regiões geográficas intermediárias 2017. Rio de Janeiro, IBGE, 2017. Disponível em: <https://biblioteca.ibge.gov.br/index.php/biblio teca-catalogo?view $=$ detalhes\&id $=2100600>$. Acesso em: 05 jan. 2019.

IVO, A. B. L. A reespacialização da estrutura fundiária do estado da Bahia. Seminário com o CREDAL-CNRS, 1983, Paria. Anais... Paris: CREDAL-CNRS, 1983.

MARTINS JUNIOR, O. E. B.; BARBOSA, N. F. Território, territorialidade e participação social: um olhar sobre São Francisco do Conde - Bahia. In: Encontro Nacional e Fórum Estado, Capital, Trabalho, 4., 2017, Sergipe. Anais... Sergipe: UFS, 2017. Disponível

em:

<https://engpect.files.wordpress.com/2017/10/ gt2-22-territc3b3rio-territorialidade-e-

participac3a7c3a3o-social.pdf>. Acesso em: 10 out. 2018.

MIELITZ NETO, C. G. A.; MELO, L. M.; MAIA, C. M. Políticas públicas e desenvolvimento rural no Brasil. Porto Alegre: Editora da UFRGS, 2010.

OLIVEIRA, G. G. de; OLIVEIRA, K. L.; ARAÚJO, L. G. Reconfiguração da estrutura fundiária no extremo sul da Bahia após intensificação da atividade silvícola. In: Congresso da Sociedade Brasileira de Economia, Administração e Sociologia Rural, XLV, 2007, Londrina. Anais... Londrina: UEL, 2007.

OLIVEIRA, I. F. Semiárido baiano: a dinâmica contraditória do desenvolvimento. Tese (Doutorado em Desenvolvimento Regional e Urbano) Salvador: UNIFACS, 2013.

PEDREIRA, M. da S. Complexo florestal e reconfiguração do espaço rural: o caso do extremo sul baiano. Bahia Análise \& Dados, v. 13, n. 4, p. 1005-1018, 2004.

PRADO JÚNIOR, C. A questão agrária no Brasil. São Paulo: Brasiliense, 1979.

PEROBELLI, F. S. et al. Produtividade do setor agrícola brasileiro (1991-2003): uma análise espacial. Nova Economia, v. 17, p. 65-91, 2007.

https://doi.org/10.1590/S0103-

63512007000100003

ROCHA, L. B. A região cacaueira da Bahia dos coronéis à vassoura-de-bruxa: saga, percepção, representação. Ilhéus: Editus, 2008.

RSJDH - REDE SOCIAL DE JUSTIÇA E DIREITOS HUMANOS; ACTION AID. Impactos da expansão do agronegócio no MATOPIBA: comunidades e meio ambiente. Rio de Janeiro, 2017. Disponível em: $<$ http://actionaid.org.br/publicacoes/impactosda-expansao-do-agronegocio-no-matopibacomunidades-e-meio-ambiente-2/>. Acesso em 10 jan. 2019.

SAMPAIO, M. G. V. Reflexões sobre o processo histórico de subdesenvolvimento econômico do semi-árido baiano. Bahia Análise \& Dados, v.18, n.2, p.211-222, 2008.

SANTOS, et al. Estrutura Fundiária nos Territórios de Identidade da Bahia. In: Semana do economista \& Encontro de Egressos, IV., 2014, Ilhéus. GT 6 - Economia Agrícola e do Meio Ambiente, Ilhéus: UESC, $2014 . \quad$ Disponível em: <http://www.uesc.br/eventos/ivsemeconomista /anais/gt6-2.pdf>. Acesso: 03 dez. 2017.

SANTOS, R. de C. E. dos. A apropriação do cerrado baiano pelo agronegócio: novos usos do território e as mudanças socioeconômicas e socioespaciais. Geografia, Ensino \& Pesquisa, v. 20, n.3, p. 08-17, 2016. https://doi.org/10.5902/2236499421491

SEI - SUPERINTENDÊNCIA DE ESTUDOS ECONÔMICOS E SOCIAIS DA BAHIA. Cidades do Agronegócio no Oeste Baiano. Textos para Discussão, n. 3, p. 01-40, 2017.

Pobreza na Bahia em 2010: dimensões, territórios e dinâmicas regionais. Salvador: SEI, 2014.

Recentes transformações do rural baiano. Salvador: SEI, 2003. 